JOURNAL OF AWARENESS

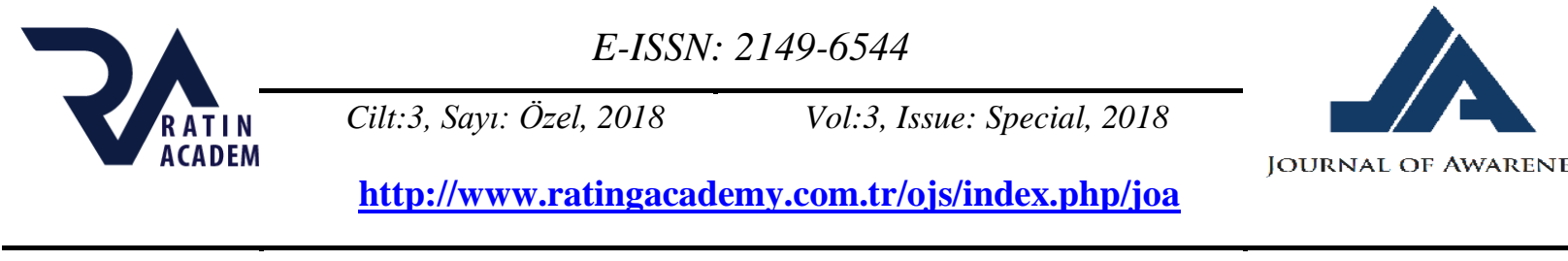

\title{
CULTURE - A REFLECTION OF THE DEVELOPMENT OF SOCIETY*
}

\section{Irena NIKAJ \\ University of Korça, Albania \\ E-mail: inikaj@yahoo.com}

\begin{tabular}{l|l}
\hline ARTICLE INFO & \multicolumn{1}{|c}{ ABSTRACT } \\
\begin{tabular}{l|l} 
Keywords: \\
culture, Lasgush Poradeci's \\
poetry, perception, society
\end{tabular} & $\begin{array}{l}\text { This paper aims to trate the issues of cultures and arts as reflection of development } \\
\text { of society in the ideas of Neo-Albanianism. The proponents of this thinking value } \\
\text { the intellectual movement as highly important in the context of their actions } \\
\text { toward the development of the country, e.g. only when they possess real mental } \\
\text { preparation can we jump into the field of practice to apply their codified thoughts. } \\
\text { The thoughts of Neo-Albanianism on culture, literature, and arts are expounded } \\
\text { generally in the form of redactional comments or recensions on particular works, } \\
\text { through which they generally achieve a sort of codification of their views on these } \\
\text { 10.26809/joa.2018548685 } \\
\text { issues. In the general sphere, their theory relies on the assertions of } \text { De Descartes, } \\
\text { E. Kant, A. Comte, and so forth, in the artistic sphere; their views are more related } \\
\text { to an evaluation of particular works from the standpoint of their philosophical } \\
\text { background. }\end{array}$
\end{tabular}

\section{INTRODUCTION}

This article aims at analysing a specific part of Albanian social and philosophical thinking in the years ' 30 of the twentieth century, namely, Neo-Albanianism and their opinion about culture, literature and arts.

The reasons for this analysis are treated below.

In post-1990 writings of a research nature, I have come across many assessments that evaluate the pluralism of thoughts that emerged in the studies and publications of the ' $30 \mathrm{~s}$, and I have seen the endeavours made by representatives of Albanian thinking to find ways of integrating Albania into Europe. In general, they were of the opinion that this integration could be achieved through progress in the area of governance, as well as through faster developments in the economic, educational, cultural, philosophical realms, etc.

If we evaluate this period and its values from the present level of the intellectual development in Europe, maybe it would not strike us as very illustrious. But, if we bear in mind the history of Albania in the second half of the $20^{\text {th }}$ century, with all those dim chiaroscuros created by the communist dictatorship, as well as the suppression of free thinking - which was widely reflected in all areas - then, we will surely become aware that Albania of the 1930's lacked numerous things. For this reason, it needed a boost on its road to development, and its advance needed more work and creative energies on the part of Albanians in general, and the people of thinking in particular. 
Among other things, the pluralistic character was a main feature of Albanian thinking in the 1930's. As such, it dealt with diverse, and even contradictory, viewpoints and theories. These conceptions were presented through theoretical debates, generally of a liberal and democratic orientation. An overarching subject in such debates was finding the most appropriate ways for Albania's development and its integration into the main current of European development.

Thus, a study of these viewpoints would have not only historical values but also, to a certain extent, actual practical values, because some objectives and developments in Albanian society in the last 10 year have a certain affinity to those of the 1930's. Furthermore, after the Second World War, for a long spell, these values of the 1930's thinking were denied; the cultivators of the thought of this period were enshrouded by silence and some of them were forced either to self-annihilate their thoughts about the liberal and democratic development of Albania or, even worse, flee their motherland.

Proceeding along the path blazed by all the previous studies, my treatise aims at continuing to give the dimensions of Albanian thinking in the 1930's, especially those of the social, philosophical, aesthetic, sociological, psychological thinking of Neo-Albanianism, through the analysis of the viewpoints of its main representatives. It is my opinion that despite its deficiencies, Neo-Albanianism tried, more than all others, to make present among Albanians Europe's (past and contemporary) philosophical and scientific viewpoints, thus creating the first beginnings of an independent reasoning, with the noble aim of creating an Albanian social and philosophical thought according to the most progressive western paradigms.

The viewpoints of the main representatives of Neo-Albanianism, which constitute the object of this study, are to be found dispersed in diverse periodicals of the contemporary press and constitute a time extension from December 1928 - when Neo-Albanian thinking was foreseen by Gjirokastra's "Demokratia" newspaper - until "The Albanian Endeavour", January-March, 1939. In December, 1928, BrankoMerxhani would write in the "Demokratia" that "the issue of Neo-Albanianism is an issue of creation. Every element it possesses is waiting the hour of its creation: past, present, and future!"

In one of the final issues of the "Albanian Endeavour", this same author writes: “... until we are able to write history, we must, first of all, do a lot of preparatory work of great importance. We have a work that will take at least another half a century. Until then, let us leave the glory of writing history to the mania and pleasure of those who are able to fill entire pages and volumes by simply dipping their mediocre pen in a black ink bottle, or in ink mixed with a few drops of... water!'(Merxhani 1938:240).

I will try to construct the analysis of their viewpoints based on the classical conception of philosophy and its constituent parts, viz., the issues of knowledge, metaphysics, ethics, science, history, religions, arts, morality, etc. The main sources for achieving my purpose were the theoretic articles published in the press of the 1930's and, first and foremost, in the "Albanian Endeavour" and "Illyria" periodicals. But other publications were also analysed, which have helped create a more complete knowledge on this issue. Furthermore, this writer also studied other works of a documentary, artistic, and cultural nature, published in the 1930's, as well as studies published later.

Other resources used were a number of works and opinions of diverse thinkers and philosophers, from Greek philosophy down to other thinkers who, in my opinion, constitute the Pleiades of thinking and reason on the relation, or relations, that they have to the issue we are studying. 


\section{CULTURE - A REFLECTION OF THE DEVELOPMENT OF SOCIETY}

Issues of cultures and arts also find reflection in the ideas of Neo-Albanianism. The proponents of this thinking valued intellectual movement as highly important in the framework of their actions for the development of the country. According to B. Merxhani, only when we have a real mental preparation can we jump into the field of practice to apply our codified thoughts. Only then may we be certain that we will succeed.

Their thoughts on culture, literature, and arts are expounded generally in the form of redaction comments or commentary on particular works, through which they, generally, achieve a sort of codification of their views on this issue. If, in the general sphere, their theory relied on the views of R. Descartes, E. Kant, O. Conti, etc., from the arts perspective, we think that their views are more related to an evaluation of particular works from the position of their philosophical background. Evaluating the quality of arts in Albania, they thought that this level was generally low. They tied the cause of this backwardness to the effect of internal factors. Thus, their view is expressed in the evaluation that a certain art, or literature, does not fall from outside causes, but from inner causes. When old ideas are exhausted and the fountain of old feelings dries out, in order to form other, much more lively, ideas or feelings, people work with what has fallen, in a spiritual vacuum. Furthermore, V. Koça opines that we live in a time when our mental sterility is most obviously reflected by the poverty of literary production (Koça 1937:204).

For this reason, they deal a little less with the affirmation of artistic values, but, at any rate, value the arts on the basis of importance of the duties they have set before themselves. According to them, it is necessary, first, to develop the culture and the intellectual development of Albanians and this, in the most natural way, is also expressed in a qualitative and cultivated literature and art, where they do not exclude the artistic culminations and geniuses.

Another aspect in the thinking of the most distinguished proponents of NeoAlbanianism is related to the issue of the development of culture in general. Beginning with $\mathrm{O}$. Comte's view and, later, opposing it, B. Merxhani would say, among other things: "...humankind does not consist of a single human society, which walks on a correct and unilateral development. There is no single human society as such... Mankind walks toward diverse directions, in fact, with aims and tools that are not very related and that do not have many affinities with one another" (Merxhani 1938:185-187).

Even though not entirely developed, this notion opposes evolutionistic theories on linear social and cultural development. In fact, it seems that this notion is contrary to the Europecentric concept of culture and, also, opposes those views that eradicate social and cultural "superiorities." We may here quote the view expressed by scholar G. Bobi on the way of unifying and organizing the thoughts of the most distinguished proponents of Neo-Albanianism on this issue. Evaluating B. Merxhani's position, G. Bobi says: "It is interesting to emphasize...we mean, the thesis that opposes the concept of culture as culture par excellence seems interesting, especially when posed by an author of the 1930's, who, in his writings, is an ardent adherent of 'Occidentalism' and of the concept on social and cultural development....(Bobi 1986:143-144). Naturally, this issue has other dimensions too.

\section{THE AESTHETIC BEGINNINGS OF ART AND THE CONCEPT OF ART}

Starting from the classical presentation of this issue, Neo-Albanianism proponents see the philosophical basis of art as connected to the issue of the nature of the perception of information, the contemplative experience in art. This is also expressed as a definition of the status of arts and the artistic work. The debate has always remained, and continues to remain, 
open to the issue of defining arts, the qualities of the activity that are incarnated in the artistic work.

Which are those qualities that turn a human creation into a work of art and the human subject, which creates it, into an artist? On this issue, the criterion of being would come to life, which must not be confused with the criterion of evaluation. Concerning this issue, the representatives of this tendency had in mind a number of definitions of arts: the earliest definition is related to the viewing of arts as an imitation; another definition is arts as expression and means of communication; another definition is the one that casts doubt on the first two, by insisting that there cannot be a definition of arts because arts and the artistic work as concepts are always changing, expanding and cannot be defined. Another definition is the one that ties arts to that which is beautiful. This last definition further complicates the answer because it also seeks by all means a definition of that which is beautiful.

In trying to formulate a definition on that which is beautiful, some aesthetes connect it to a mystical, inexplicable beginning. We think that Neo-Albanian views find their place within this concept. Furthermore, we find common points between their views and the views of A. Schopenhauer.

Let us shortly analyze some of these reflections on arts and the artistic work.

First of all, there is the issue of treating arts in the light of scientific arguments. From the cognitive point of view, we say that man is characterized by the desire to know objects, life, and being. This happens because being represents interest to the intellect in itself, i.e., for the subject of cognition freed from the objects of research, while for the cognitive subject as a simple individual, only the objects of research are important. As a consequence, according to this, the result, the end of any objective cognition of objects, things, as well as any cognition through an artistic work, is more an expression of the essence of life and being and is reduced to an answer to the question: "What is life?" According to the main Neo-Albanian proponents, this question is answered in its specific, fully justified, way by every real and accomplished work of art.

Congratulating the publication of the poetic volume, "Star of my heart," by L. Poradeci, B. Merxhani writes: “... His poetic structure (of L. Poradeci - I. N.) is built on the matter that he gathered all over the place among the dark ruins of our soul... The main importance of his poetic work is not in his accomplished lyricism, nor in his deep philosophical thoughts. Lasgush is the rustic poet..., who displays the truth of the rustic world"(Merxhani 1938: 307, 308).

Secondly, a characteristic of the arts is that they all speak only in the genuine and infantile language of the intuition, not in the abstract and serious language of the thought. Their answer is a passing image, not a general, stable knowledge. Thus, every work of arts, every tableau, every statue, every poem, every theatrical stage, answers these questions only through intuition.

Thirdly, of all the other arts, music answers more properly the question, "What is life?" because, with its easily understandable language, it cannot be translated into the language of reason, and it expresses the most intimate essence of all life and being. In fact, within this orientation, M. Kuteli opines that L. Poradeci's poetry has a musical nature. Here is what he writes: "Many of the older readers of Lasgush have long noticed that his work has a special sounding magic, a magic of its own, which is musical - as the others say. The musicality and plasticity of this work is the mirror of the inner assault, the spiritual assault of the poet, expressed through the word, which are woven "one by one, and verse by verse, harmonized with the content and with the meaning of the work" (Kuteli 1938: 252). 
Fourthly, all arts answer this question, but their answer is temporary, not complete or definitive. This is due to the fact that the arts always give a fragment, a paradigm, instead of the rule or the whole, which may be given only by the generalization of concepts, which thing is processed by sciences.

Fifthly, a stable and permanently acceptable answer needs a deeper and in abstracto thought, which belongs to the realm of philosophy. The roots of philosophy and the beautiful arts are the same, but they differ in terms of abilities, directions and every other secondary thing. According to this reasoning, every artistic work has its own philosophical basis. The endeavor of the most distinguished representatives of Neo-Albanianism also aims, for example, at the discovery of "the world of poetic inspirations of our poet" (of L. Poradeci - I. N.), the collection of the principles agreed to by him, and "Lasgushi's poetry which is closely connected to his mental and spiritual formation"(Merxhani 1938: 253).

Sixthly, every work of art tries, in the real sense of the word, to show life and objects just as they truly are, but that may not be understood immediately by everybody, because of the fog of objective chance events. Among the arts, the works of the author of figurative arts and poetry keep open a treasure of the deep knowledge, exactly because the knowledge of the nature of objects speaks through them, from where they can only interpret expressions through clarification and the purest repetition.

In order to extract knowledge from works of arts of such a nature, one should understand the symbolics of their means, but this is defined by the level of education and the ability of each individual. In front of a tableau, everybody should stand as in front of a prince, expecting what to say to him and how, in case he wants to say something to him, and he himself should not address the prince first, because then he would be only hearing himself. In order to not misunderstand this thought, we would add that this is not the same as the meaning of the art for art, a view which found echo and was discussed in the press of the years 1930, as researcher and sociologist G. Bobi says (Bobi 1986: 181).

We may mention here the polemic between a group of intellectuals who advocated the view of art for art, expressed especially in the writing of K. Maloku, as well as the views of the most distinguished proponents of Neo-Albanianism, who advocated the view of art in relation to life. In his article, "Language," published in the "Demokratia" newspaper on May 13, 1933, B. Merxhani wrote: "Popular Poetry and European Poetry - here are two different Art Museums, within which our national literature may be formed and developed and prepared for a period of flourishing, a period which will not only solve the present turbulent issue of language, but in due time, it will notify us about the dawning of a new life and a new destiny" (Merxhani 1933: 5).

Seventhly, the knowledge contained in figurative arts is virtual and internal. In order to make it actual and explicit, we need the help of philosophy. What philosophy promises to deliver would be a benefit almost already achieved, a stable and long-lived property; whereas what is derived from the creations and the works of art should be newly reproduced. Exactly because of this, philosophy has demands that leave on dumbfounded, demands that are difficult to be fulfilled, not only by those who create works of art, but also by those who enjoy them. That is why the publication of philosophy remains scant, while that of the arts is prolific.

Eighthly, besides his direct contact with the work of art, the subject who establishes the contact with the work of art should also have the medium, the means of fantasy. This is a condition of the aesthetic effect and, for this reason; it constitutes a fundamental law of the beautiful arts. This also means that senses are not given everything, and that senses cannot catch everything. Fantasy is always left with something to do; in fact, the final step belongs to it (Merxhani 1937: 170). 
Ninthly, the good in art is spiritual and, thus, not all of it is given to the senses. Sculpture and picture, especially, tend to activate fantasy, while poetry only addresses itself to fantasy, which it puts into action by means of simple words. Expressing this theoretical vision B. Merxhani writes that L. Poradeci is "the Albanian poet who holds alive, within him, the spirit of an artist, who desires to summarize the aesthetic spirits that fly as in flight in the dry wind of this country. Lasgush is one of those who began his journey without looking any more toward the desolate fields of our regions (Merxhani 1938: 307, 308).

Tenthly, art has, in its origins, the intuition, which is expressed through ideas. Artistic ideas are essentially intuitive and, as a result, inexhaustible in their approximate indefinableness. Knowledge about them can be achieved only through the path of intuition, which is that of art. He who is involved and filled by an idea is excused if he chooses art as the means of representing and expressing his ideas (1938a). If, in the evaluation of a work of the plastic art, or in the reading of a poem, or in the listening of some music (which tries to describe something definite) we see the hidden appearance and, finally, the full appearance (through all the rich means of art) of the clear, limited, cold, and simple concept, which was the nucleus of the whole work, then, the whole creation was solely supported on the clear thought in regard to it and, hence, is expressed in its presentation. We are fully satisfied by the impressions of a work of art only when it leaves something which, we, despite all our meditation on it, cannot use it to arrive at the clarity of a concept.

Lastly, necessity is the mother of the useful arts, while the mother of the beautiful art is excess. The former have to do with the intellect, while the latter with genius, which is itself a kind of excess, viz., an excess of the power of cognition on the measure required to serve the will and the desire (Schopenhauer 1995: 52-58). These views are expressed in some writings of some proponents of the Neo-Albanian thought, such as in the writings of B. Merxhani, M. Kuteli, and S. Luarasi.

\section{The transcendent spark descends from the heights}

In the 1930's, the poet L. Poradeci published two volumes of poetry: "Dance of the Stars" (1933) and "Star of the Heart" (1937). One Neo-Albanian proponent, M. Kuteli, in the pages of the "Albanian Endeavor" magazine, often tries to throw light on the features of L. Poradeci's artistic creations; these features, in our opinion, reflect the aesthetic views of NeoAlbanianism. This idea is also affirmed by researcher G. Bobi in his monograph with title "Cultural paradox."

The endeavor to evaluate L. Poradeci's creations includes the analysis of principles, spiritual elements, the philosophy embodied in his works, its contents, his mental and spiritual formation, etc. According to B. Merxhani, the analysis of L. Poradeci's inspiration demonstrates his transcendent nature which means that it is a state of being beyond the scope and understanding of our experience. When L. Poradeci speaks about a transcendental sparkle, we may see this as a rational principle that organizes our experience, despite the fact that this is insufficient to achieve cognition.

A star descends from heights above,

A shining flash of light -

As a flame and a shadow,

It lightens up my heart.

I can see it, with my tired soul,

As it very slowly drips,

It opens, in the folded word,

The corner of a pleat (Kuteli 1938:243-244). 
Further, we may concentrate on some of the elements of fantasy that appear in L. Poradeci's poetry. First of all, there are a number of elements that are related to the poet's early experience, especially the fantasist interpretation of his childhood events or experiences. Relying on the richness of the Albanian language, he accomplishes a universe of verses where the elements gain a multifaceted nature; they are direct components of the real, physical, world, and are also imaginary components, passing through a series of transformations, gaining extrahuman dimensions and qualities, or rising up to the level of the most abstract symbol.

The poet views the falling of dusk as a veil spreading out like a shadow; the dark lake in the evening on the mountain reminds him of the fluid and divine spirit and, yet, as shut within his chest; the stars of the sky, fading in the morning, are like darkened eyes; the pelican is the morning's herald; the stork walks like a bridegroom with a crown and crane; alongside him, a world appears, like a newly wedded bride which, according to M. Kuteli, is also similar to the Buddhist spiritualistic-meditative scenes. B. Merxhani quotes L. Poradeci's thought, who said that "on the one hand, we must awaken our people's aesthetic motives and, on the other, to make them understand the masterpieces of the European literature." According to B. Merxhani, these qualities, exhibited in L. Poradeci's aesthetic thinking and artistic work, make him the only artist of the generation of the ' 30 s who had a pure human-aesthetic height and depth.

Where and how is the beautiful aspect exhibited in L. Poradeci's poetry? According to M. Kuteli, it is expressed in a harmonization of form and content. This exact interweaving has as its primary element the fact that L. Poradeci's poetry expresses the troubles of the soul, the joy and bitterness, and the most refined emotions of the man-poet (Kuteli 1938a).

According to the main proponents of Neo-Albanian thinking, in general, L. Poradeci is an expressive poet, namely, he dimensions a spectrum in extreme limits or in a macrocosmic space, like a rainbow spread among the stars and the knowledge of the universe, or this happens more often in the condensed density of a teardrop. This demonstrates a tendency conditioned by the poet's desire, which is ubiquitous in order to transport the expressiveness of the poetic verbality beyond the boundaries of the impossible.

According to M. Kuteli, L. Poradeci's poetry originates from the popular substratum, which continued to feed his poetry. Reading L. Poradeci's poetry through time we think that, despite the distinguished diversity of the interpretation of the messages it has provoked, at one point it has shown the tendency to converge; we have to do with a creativity that, beyond the moment, aims at eternity and, beyond the local, aims at the universal (it is similar to G. W. F. Hegel's scheme about the rapports between the particulars and the universals). In our opinion, the colours of L. Poradeci's poetry in the two volumes published during the 1930's are very near the conceptions and structures of oral popular poetry. (In fact, L. Poradeci deems the creation of the rhymed poetry as the truest of all poetry, and he cites Bualo saying, "Rhyme is a slave and it must only obey," that is, he values the feature that characterizes, first of all, the Albanian popular poetry (Kolevica 1992: 101.) In poetry of L. Poradeci, as a rule, the symbolics of the spectrum of colours is not encountered in the elementary functions; I. Kadare has said that Lasgush always told him, in their conversations, about his first fiancé, a painter, who was blonde and, then, became dark-complexioned when they separated (Kadare 1991: 18). His vision for colours, in our opinion, is completely conceptual and abstract, but with certain emotional connections.

According to M. Kuteli, the perceptibility of this mixture of colours and lexicon has an expressiveness that springs from within and, if you remain within the limit of a simple perception, then you may arrive at the conclusion that we are in the area of the poetic constructions that lack logic, for example, in the verses: 
Ah! You cannot stop my terrible pain

From becoming fire and light - even a white light! (Kuteli 1938: 243-244)

Similar to this are also other constructions of a paradoxical kind, such as, "the clean fez, the blackened fez." According to formal logic, the fez cannot be at the same time clean and blackened. But this form achieves expressiveness also through the other verse, "the lip that smiles and sighs"; this is a meditative feature of L. Poradeci's poetry. In such synthetic constructions, the expressive function of colour is intertwined with function, which becomes more perceptible in the following verses:

Her white skin, her red skin,

Her under-chin like a lily, her lips like a flower bud.

Further, in L. Poradeci's poetry, elements of the lyrical hero's spirit are also expounded. The wide gamut of the elements that characterizes his verses concentrates on the poet's spirit as their object. They are part of an almost cosmic imagination that is realized through strong, and apparently impressive, feelings, such as, for example, in the following verses:

Black dust covers your solitary eyes,

You solitary eyes kindle stars on the sea waves,...

When I saw them, oh! In a night of wormwood, the distant moon was cast in gold.

When I saw them in a night of wormwood, my mourning turned into cast gold.

Dwelling on L. Poradeci's poetry, B. Merxhani underlines that a characteristic of his poetry is transcendental conception in its beginning, as well as in its general concept. Among other things, B. Merxhani writes: “... when we say that Lasgush's poetic inspiration descends from the transcendental world "like a sparkle from the heights", etc...," we must understand that the world of our poet's poetic inspirations consists of a group of principles that are accepted a priori, of unshakeable, true, and simple spiritual powers that pervade and completely dominate the poet's mental being."

In our opinion, B. Merxhani views the a priori conception of the world of perceptions as a quality of L. Poradeci's poetry, which gives it its main features. This is an intertwining of this view with that of E. Kant, when he mentions not only the "sinnlicheErfahrung", but also with that of E. Kant's work, "Kritik der reinenVernunft".

Further, B. Merxhani notes: "Transcendentalism is a kind of view that relies only on the conscious notions and contents without asking whether these have some kind of objective support or not. Transcendental ideas become empirical images only when they are connected to objective things understood by means of some mental experience" (Merxhani 1938: 253).

In fact, B. Merxhani and M. Kuteli consider the analysis of Lasgush Poradeci's poetry as something completed. It has clear elements of the concepts of the world and art similar to the views of the main proponents of Neo-Albanianism. At the same time, it needs deeper analyses of a philosophical character, which should take into consideration the poet's mental and spiritual background, and it should also be a creativity that is completed by the poet's ongoing creativity(1938a). This vacuum is somewhat filled in our days, even though, neither we, nor the others who have dealt with the deep artistic and philosophical analysis of L. Poradeci, have not pretended that the area of his study has been exhausted.

Roy Fuller - known for his syllabic verses in his work "Owls and Artificers" - has written that poetry is music in words and that music is poetry in sounds. Both are good sauces, but those who cooked their soup with these two sauces, have died young (Luzaj 1999: ). In order to understand poets, their Ego in poetry should be understood. In order to understand the poet's Ego, the human being must be mentally prepared to take a walk and to strongly leave the 
passions of his own time, be they of a religious, political, social, racial, or national nature. Maybe this was why the great poet, Poradeci, used to say that they would build his monument only after 50 years.

At the end, according to Robert Elsie, Lasgush Poradeci is at the same time an artist of truly European stature. He combined the verbal sensuousness of Charles Baudelaire, the aesthetic philosophy of form and the discerning elegance of Stefan George, the humanity and philosophy of Naim Frashëri, and the cosmic immortality of his master, Mihai Eminescu. Scholar Eqrem Çabej said of him that he was the "poet whom Albania would one day bequeath to the world," and although Poradeci's verse does not lend itself particularly to translation, time may prove Çabej right (Elsie 2003: 13-14).

In the Albanian development cicumstances of the years 1930-s, Neo-Albanians chose the pluralism of opinions, which were introduced in that time publications, especially in the "Albanian Endeavour" magazine. According to Neo-Albanians, the formula needed was progress-order-law, which viewed from the Albanian cicumstances, means that the progress could be supported and realized by any kind of bourgeois regime. Mostly, Neo-Albanians thought that the way to bourgeois development was the principle to the progress of the Albanian socety which enhances the slowness, really it is following this way. 


\section{REFERENCES}

Collection of magazine Albanian Endeavour 1933-1938

Comte, A., 1877, System of Positive Polity. New York: Harper and Row.

Descartes, R., 1979, Meditations on First Philosophy. H. P. Com Inc.

Elsie, R., 2003, Albanian literature: an overview of its history and development, in: Österreichische Osthefte, Vienna, 45, 1-2, 243-276.

Kadare, I., 1990, Invitation at the studio. Naim Frashëri.

Koça, V., 1999, In the road of Albanianism. Phoenix \& House of Book.

Merxhani, B., 1996, The formulas of Neo-Albanianism. Apollonia.

Nikaj, I., 2013, Albanian Social and Philosophical Thinking of '30s-Neoalbanianism, AuthorHouse, Bloomington, IN 47403.

Schopenhauer, A., 1962, The Essential Shopenhauer. Unwin Books, London.

Welsch, W., 1997, Unsere postmoderne Moderne. Berlin: Akademie Verlag.

Wright Mills, C.,1973, The Sociological Imagination. Penguin Books. 